Revue

Revue de l'histoire des religions

de Ihistoire des religions

$3 \mid 2016$

Varia

José FERNÁNDEZ UBIÑA, Alberto J. QUIROGA PUERTAS, Purificación UBRIC RABANEDA (coords.), La Iglesia como sistema de dominación en la Antigüedad Tardía

Granada, Editorial Universidad de Granada, (« Historia »), 2015

Sylvain Destephen

\title{
OpenEdition
}

Journals

Édition électronique

URL : http://journals.openedition.org/rhr/8589

DOI : 10.4000/rhr.8589

ISSN : 2105-2573

Éditeur

Armand Colin

Édition imprimée

Date de publication : 1 septembre 2016

Pagination : 425-428

ISBN : 978-2-200-93061-5

ISSN : 0035-1423

Référence électronique

Sylvain Destephen, « José fernández ubiña, Alberto J. quiroga puertas, Purificación ubric rabaneda (coords.), La Iglesia como sistema de dominación en la Antigüedad Tardía », Revue de l'histoire des religions [En ligne], 3 | 2016, mis en ligne le 06 octobre 2016, consulté le 25 septembre 2020. URL http://journals.openedition.org/rhr/8589; DOI : https://doi.org/10.4000/rhr.8589

Ce document a été généré automatiquement le 25 septembre 2020.

Tous droits réservés 


\section{José FERNÁNDEZ UBIÑA, Alberto J. QUIROGA PUERTAS, Purificación UBRIC RABANEDA (coords.), La Iglesia como sistema de dominación en la Antigüedad Tardía}

Granada, Editorial Universidad de Granada, (« Historia »), 2015

\section{Sylvain Destephen}

\section{RÉFÉRENCE}

José FERNÁNDEZ UbiÑA, Alberto J. QUIROGA PUERTAS, Purificación UBRIC RABANEDA (coords.), La Iglesia como sistema de dominación en la Antigüedad Tardía, Granada, Editorial Universidad de Granada, (« Historia »), 2015, 24 cm, 358 p., $23 €$, ISBN 978-84-338-5763-7.

1 Ce volume rassemble une quinzaine de communications prononcées lors d'un colloque international organisé par l'Université de Grenade en mai 2014. On appréciera la rapidité et la qualité de publication des actes de cette rencontre, d'autant que les trois éditeurs scientifiques ont fait le choix de présenter toutes les contributions en langue espagnole, ce qui les a obligés à en traduire un tiers environ. Néanmoins le titre, qui reprend celui d'un projet de recherche dont le livre constitue à la fois la finalité intellectuelle et l'aboutissement matériel, semble mettre en accusation l'Église, une fois encore vilipendée pour ses abus de pouvoir et dénoncée pour ses excès d'autorité. Les éditeurs s'en expliquent brièvement dans la préface en renvoyant au concept de système de domination théorisé par Max Weber.

2 Le livre se divise en trois parties de taille et parfois de valeur quelque peu inégales : la première partie, avec quatre contributions, entend étudier l'Église de la basse Antiquité comme système de domination en parallèle avec d'autres institutions non religieuses, 
en particulier l'État romain tardif. La deuxième partie, qui comptabilise un nombre équivalent d'articles, examine le rôle joué par les évêques et les moines vus autant comme des artisans que des agents de la domination ecclésiastique. La dernière partie, forte de six contributions, passe en revue divers « instruments » de domination, comme la transformation de l'espace public ou la fondation de lieux de culte, la prédication ou la répression par le discours et la loi.

3 Le premier article, de Gonzalo Bravo, revient sur l'idée wébérienne de l'institution ecclésiastique comme "système de domination » soutenu par l'État romain. Avec la disparition de l'Empire, l'Église devient un « système de pouvoir alternatif ». Le passage de l'un à l'autre aurait nécessité l'acquisition de nouvelles compétences, en particulier l'exercice de la violence publique pour imposer sa volonté : l'Église serait devenue un « système autoritaire » (p. 25 et 40). Si cette lecture orientée de l'histoire ecclésiastique eût plu aux historiographes chrétiens de l'Antiquité tardive en raison de son caractère téléologique plus qu'idéologique, elle offre néanmoins une interprétation trop univoque par volonté de généralisation ou d'abstraction. Le doute est également permis devant les conclusions d'Andrew Fear qui défend l'adhésion de l'empereur Constantin à l'arianisme parce que cette doctrine aurait affaibli l'autorité et l'opposition de l'épiscopat (p.47). L'auteur oublie l'existence du nombreux clergé arianisant de la moitié orientale de l'Empire. L'arianisme et l'épiscopat sont ensuite examinés par Pedro Castillo Maldonaldo dans le cadre de l'Espagne wisigothique et de la conversion de ses souverains au catholicisme. Cette conversion aurait marqué la fin d'une période de tolérance, sans doute un peu idéalisée, et l'établissement d'une théocratie autoritaire (p.56 et 70). Cette partie consacrée à l'Église, structure dominante ou dominée, se termine par un article de Luis García Moreno sur les chrétiens d'Al-Andalus confrontés à la dislocation des structures ecclésiastiques, préambule à leur islamisation à partir du $\mathrm{X}^{\mathrm{e}}$ siècle (p. 98-99).

4 La deuxième partie examine la montée en puissance des évêques et, dans une moindre mesure, des milieux monastiques durant l'Antiquité tardive, en Orient puis en Occident. Les grandes étapes de constitution d'une autorité religieuse monarchique au sein puis au-dessus de chaque communauté chrétienne durant les trois premiers siècles d'existence de la nouvelle religion sont retracées par José Fernández Ubiña. Ce dernier rappelle comment la sacerdotalisation de l'évêque aboutit à sa progressive sacralisation aux dépens des prêtres, tandis que son association au sacrifice aboutit au monopole eucharistique (p. 108 et 112). Le parallélisme qui est ensuite établi entre l'autorité monarchique de l'évêque et le pouvoir autocratique du souverain au Bas-Empire semble en revanche excessif, comme l'auteur le reconnaît (p.129). La fonction épiscopale s'affirme dans un cadre territorial déterminé, mais s'affaisse quand elle se multiplie dans un même ressort. Alberto Quiroga Puertas illustre cette situation par l'exemple, certes extrême, de coexistence à Antioche entre 330 et 415 de plusieurs évêques (et communautés) se réclamant de la doctrine du concile de Nicée. Loin de se borner à des événements connus, l'auteur montre comment, à la suite de Peter Van Nuffelen, la réinterprétation du schisme antiochien par l'historiographie ecclésiastique du ve siècle traduit la persistance d'un débat sur l'héritage nicéen déposé entre les mains de l'épiscopat et son actualisation comme source de légitimation de l'épiscopat (p. 140 et suivantes). Passant du côté occidental, Purificación Ubric Rabaneda montre la rapide adaptation des évêques aux rois barbares avec qui ils auraient entretenu une relation « cordiale» (p. 159). L'alliance de la francisque et du goupillon aurait permis d'exercer de conserve une domination politique assurant la stabilité sociale par l'incorporation 
des élites romaines dans l'épiscopat et l'acceptation par les évêques d'une relative diversité des confessions chrétiennes (p. 163-167). Dans ce cas, l'Église nicéenne est-elle dépourvue d'autorité, coupable d'opportunisme ou dotée d'un surprenant esprit de tolérance? La réponse fait défaut. La volonté de dominer semble contrebalancée, du moins dans les monastères ibériques, par le devoir de secourir les nécessiteux, mais certaines règles monastiques de l'Espagne wisigothique ne permettent pas toujours de savoir si les personnes soulagées sont étrangères ou intégrées à la communauté (p. 180).

5 La dernière partie examine divers moyens dont dispose l'Église pour exercer sa domination sur la population laïque. À l'échelle des diocèses, Immacolata Aulisa livre une étude de géographie historique et ecclésiastique sur les similitudes et les dissemblances observées dans plusieurs régions (Italie annonaire et suburbicaire surtout, Maurétanie césarienne) entre la cité et l'évêché, entre le territoire municipal et le ressort épiscopal. L'auteur met en garde contre les interprétations trop mécaniques du principe d'accommodement observé par l'Église depuis la conversion de l'Empire au christianisme (voir en particulier p. 197-205). La question de la polarisation et de l'expansion de l'autorité épiscopale est également examinée par Chantal Gabrielli à travers le cas particulier du culte des martyrs en Afrique du Nord, une région confrontée au dédoublement des hiérarchies, aux dévotions concurrentes et à la construction de mémoires saintes exclusives en raison du schisme donatiste (voir p. 224-225). Sur ce point, il est possible de compléter l'article par la lecture de la récente étude de Bruno Pottier, "Cultes civiques, régionaux et locaux en Afrique du Nord durant la crise donatiste (IV ${ }^{\mathrm{e}}-\mathrm{V}^{\mathrm{e}}$ siècles) ", dans Des dieux civiques aux saints patrons, Paris, 2015, p. 139-166. L'autorité ecclésiastique exercée sur le quotidien sacré des individus se manifeste non seulement par l'orientation de leur piété, mais également par l'exercice d'un ministère du discours sacré qui impose aux prédicateurs de l'Église de maîtriser les techniques oratoires nécessaires pour obtenir la conviction, l'adhésion ou la soumission de l'auditoire. Jamie Wood étudie deux traités, deux manuels catéchétiques rédigés par les évêques Augustin d'Hippone vers 400 et Martin de Braga vers 575 à la demande de confrères encore mal formés pour inculquer les rudiments de la doctrine chrétienne aux simples ou aux récalcitrants. La place du discours dans l'autorité ecclésiastique prend un sens particulier dans le cas des femmes qui, à travers la figure de la martyre, de la sainte, de la vierge consacrée, enfin de la mère de famille, se voient proposer des exemples de perfection successifs qui ont en commun, selon Amparo Pedregal, d'entretenir une image de soumission et de faiblesse de la femme placée sous tutelle masculine. Le souci d'organiser, d'ordonner, de réprimer si nécessaire, apparaît dans la législation civile et surtout conciliaire de l'Espagne wisigothique examinée par Céline Martin qui, dans le cas de la lutte contre le paganisme, montre comment l'ancienne religion devient progressivement un ensemble de croyances disjointes puis une création théologico-juridique qui légitime l'autorité de l'Église (p. 275). Il revient à Raúl González Salinaro le soin de conclure ce livre consacré à l'avènement dans l'Antiquité tardive de l'Église comme système de domination par une étude de la dépréciation du judaïsme consécutive à l'officialisation du christianisme et préalable à des poussées de violence et d'intolérance dont l'épiscopat est jugé collectivement responsable (p. 306). 


\section{AUTEURS}

\section{SYLVAIN DESTEPHEN}

Université Paris Ouest Nanterre. 